\title{
Wave height incidence on Mediterranean Short Sea Shipping routes
}

\author{
F. Xavier Martínez de Osés and Marcel.la Castells \\ TRANSMAR research group - Department of Nautical sciences and engineering \\ Pla del palau, 1808003 - Barcelona, Technical University of Catalonia
}

\begin{abstract}
According to the recent mid term review of the EU white paper on transport, Short Sea Shipping in EU waters is expected to grow from 2000 to 2020 at a rate of 59\% in volume (metric tonnes). If we consider that the overall expected growth in freight exchanges is of 50\% (also in volume), sea transport is one of the most feasible ways to reduce traffic congestion on European roads. High speed vessels are a possible way to compete with road transport in certain traffics; however these ships are highly affected by heavy weather. This paper is going to analyse the weather influence on several short sea shipping Mediterranean routes to be served by fast ships.
\end{abstract}

\section{KEY WORDS}

1.Short sea shipping, 2.Fast ships, 3. Significant wave height

1. INTRODUCTION. The European Commission and Member States have observed that transport in Europe is growing at a high rate and that by 2020, the figures for inter European transport, including the EU new Member States, will show a growth of over $50 \%$ in volume, and that these values would be absorbed mostly by road transport. However, road transport poses rather more environmental problems than maritime transport, such as a higher rate of traffic congestion, pollution, noise, or accidents. Although Europe needs all modes of transportation to ensure the necessary mobility for people and business, short sea shipping integrated into an efficient transport chain appears to be a potential choice for avoiding congestion, improving accessibility and providing seamless transport routes.

There are certain commodities and traffics, where the superior cost of sea transport within an intermodal transport chain (due to legal systems, infrastructure differences or less developed transport) (Blonk, 2003), could be assumed by using more expensive transportation units such as high speed vessels.

The main aim of this paper is to carry out an analysis of the sea conditions in the western Mediterranean, in order to assess the provision for fast vessels in 5 feasible routes, and their competitiveness in front of road transport. The paper has been divided into two main sections. Firstly a brief description of the selected Short Sea Shipping routes in SW Europe and some previous research are provided Secondly, an analysis of the sea conditions that would affect the proposed routes, mainly regarding wave height and their effects on high speed vessels.

2. STATE OF ART OF SHORT SEA SHIPPING IN EUROPE. The current state of Short Sea Shipping within Europe is briefly reviewed in this section. Short Sea Shipping accounted for $19.5 \%$ of the entire volume of 
goods transported by sea within the EU-25 in 2005. The total amount of goods transported by sea was of 1.46 billion tonnes (NEA Institute, 2006) in front of a 58.2\% carried by road, which was in the first position with 4.36 billion tonnes. In terms of tonne-kilometres, intermodal rail, barge and shipping transport only accounted for $5 \%$. But based on an analysis of transport flows and the development of transport demand according to the type of freight, the aforementioned study forecasts that between 2005 and 2015 the total shortsea tonnage will increase by $31 \%$ on average.

The distribution in 2005 by modus is shown below.

\begin{tabular}{|c|c|c}
\hline $\begin{array}{c}\text { Transportation } \\
\text { modus }\end{array}$ & $\begin{array}{c}\text { Market share by } \\
\text { modus }\end{array}$ & $\begin{array}{c}\text { Volumes by modal } \\
\text { split }\end{array}$ \\
\hline Road & $58.2 \%$ & $4,359 \mathrm{MTm}$. \\
\hline Shortsea & $19.5 \%$ & $1,464 \mathrm{MTm}$. \\
\hline Rail & $12.2 \%$ & $916 \mathrm{MTm}$. \\
\hline Inland navigation & $5.5 \%$ & $414 \mathrm{MTm}$. \\
\hline Other & $4.6 \%$ & $343 \mathrm{MTm}$. \\
\hline
\end{tabular}

Table 1: Distribution of transportation modus by market share and volumes in EU -25, 2005. Source based on NEA.

The expected evolution, points to a slight increase in the shortsea shipping share and a road transport slight lose of only $1 \%$ of its market share. In spite of this, there is a long way to go to reach a sustainable transport network in an enlarged Europe (soon to be 27). There are major concerns related to transport, such as pollution or congestion in the Western territories or good accessibility in the other ones.

The European Commission knows that a quick and effective way to improve the transport policy passes by the increased use of short shipping routes and so-called fast ferries. However, many of these vessels are considerably more sensitive to local wind and wave conditions than older longer haul shipping, supposing a requirement for improved accuracy and higher resolution, short and medium term meteorological forecasting.

Sea routes conditions on European short sea shipping connections are determined by waves (wind waves and swell) and currents, and by the sea surface winds. Waves and their impact are qua ntified by their energy spectral data: wave height and shape, wave length, period and direction and the dynamic change of those parameters. Assessing those data by various methods and showing them by computer modelling in a synoptic context will represent the nowcast, whilst prognosis gives a forecast with necessarily more uncertainty. Data assessment is obtained by different measurements from different platforms, such as buoys, ships, airplanes or satellites. Different sea regions with different meteorological regimes must be distinguished: open seas (North Atlantic) and enclosed seas with deep sea and shallow water areas (Mediterranean, Western Baltic, Irish Sea), where the meteorological data, their assessment and their quality control are different.

2.1. MOTORWAYS OF THE SEA. This concept was first introduced in the White Paper on European Transport Policy towards 2010. According to this document, sea transport is not just a means of carrying goods 
from one continent to another but a real competitive alternative to land transport. For this reason, certain shipping links should be included as part of the trans-European transport network, just like motorways or railways, in an effort to reduce road congestion and/or improve access to peripheral and island regions and countries. In addition to land transport connections, also sea connections, or "the Motorways of the Sea", are now included in the TEN-T ${ }^{1}$ network. This enables the logistic s connection of different priority land transport projects, which will contribute to the improvement of the overall efficiency of EU transport network operations. The Motorways of the Sea are different from other priority transport projects and their rules have been described in the Article 12a of the TEN-T guidelines.

The retwork shall consist of facilities and infrastructure concerning at least two ports in two different member countries. Keeping in mind the close date for publishing the list of ports included in the MoS network we are going to analyse what type of vessel is going to fit best in some of the proposed ports, for ensuring a real modal shift. Once understood the sea transport importance, the sea conditions and specifically the wave highness analysis, is the topic to be dealt in this paper, as a contribution to recommend the ship better fit on a route, keeping in mind her sensitivity to sea and waves.

3. PREVIOUS RESEARCH AND SELECTED ROUTES. The previous research carried out by the TRANSMAR research group integrated in the Technical University of Catalonia was the INECEU project, proposed after an exhaustive study of alternative multimodal lines against road transport (Olivella, Martínez de Osés, 2005) ${ }^{2}$. Keeping in mind the figures of road traffic accross the Pyrenean borders, the group analysed most of the cargo volume transported between Spain and France. Among all the Spanish regions we should note the activity of Catalonia, the Basque country, Valencia and Andalusia. The ir cargo volumes could be moved by sea transport through the ports on the Mediterranean coast. Regarding the nature of the cargo, we should note that the South and South-East of the Iberian Peninsula together with the Valencia coast are big producers of fruit and vegetables. Actually, the group of manufactured or canned food and alcoholic drinks is one of the larger cargo groups that exports products from Spain. Besides, there is important traffic involving solid bulk such as building materials or scrap iron together with oil and chemical products from ports with refineries nearby that are firmly committed to removing trucks carrying dangerous or toxic substances from the road in favour of ships with specifically-designed containers, or Ro/Ro's, ${ }^{3}$ that will benefit transport activity as a whole. The study concluded that:

a. The Short Sea Shipping in the Mediterranean basin needs destinations further than 800 kilometres to be economically justified. Keeping in mind the driving limitations and periods of rest, that figure comes from

\footnotetext{
${ }^{1}$ TEN-T: Trans European Network - Transport.

2 Intermodalidad entre España y Europa. El proyecto INECEU (Intermodality between Spain and Europe. The project INECEU)

Barcelona digital, SL Editors. Barcelona 2005. Also a report available at https://e-prints.upc.edu/handle/2117/524.

${ }^{3}$ Ro/Ro ship stands for Roll on roll off, meaning that cargo enters and exits the ship on wheels.
} 
the maximum distance at which a truck can travel in a working day. After this point the driver must stop and continue next day, while the ship can sail at a less speed but the entire day.

b. The geographic and economic conditions in the Mediterranean are variables promoting boosting sea transport and thus reducing the Pyrenean congestion, but this still implies only a small participation on the overall figures.

c. Fast ships in this kind of traffic could be justified in serving trips of less than 12 hours and when cost is not so important provided a minor time of delivery can be guaranteed. The 12 hours limitation come from the safety legislation, once exceeded a second crew is needed, multiplying the operational costs. The reduction in sailing time for the considered speeds is around $50 \%$, because the different cruising speeds on INECEU project considered ships (18 knots in conventional ships to 40 knots on fast ships). The operational cost doubles the conventional ship ones.

d. Weather conditions should be kept in mind mostly when fast vessel traffics are considered.

4. ANALYSIS OF MORE SUITABLE ROUTES. From the mentioned study, up to 15 routes were obtained based on the best time and cost performance between multimodal against road transport. This paper is going to present a part of a more in depth analysis initiated after the $\mathrm{PhD}$ candidate Marcellla Castells, who analysed more variables, obtained some preliminary results. Now we are going to show the weather variable incidence on the routes.

In the initial stages of the study only 5 routes were considered as alternatives to road transport. Those 5 routes are shown in the next table including an Atlantic route to be compared with the Mediterranean ones.

\begin{tabular}{|c|c|c|c|}
\hline Origin area & Loading port & Discharge port & Destination \\
\hline Madrid (Centre Spain) & Valentia & Naples & Naples \\
\hline Barcelona (NE Spain) & Barcelona & Civitavecchia & Rome \\
\hline Alicante (E Spain) & Alicante & Genoa & Milan \\
\hline Burgos (NE Spain) & Tarragona & Genoa & Milan \\
\hline Benavente (NW Spain) & Gijon & Hamburg & Berlin \\
\hline
\end{tabular}

Table 2: Multimodal chains found more efficient than road transport Source: Own analysis, 2006.

Weather limitation is a factor to be kept in mind when analysing a sea route, but its importance grows when the route could be served by high speed vessels. These are subject to restrictions derived from the significant wave height as the HSC Code points out. This means that in certain meteorological conditions a ship will not be able to sail or she will need to look for shelter while being at sea. Then it is necessary to know the potential time this kind of ships will be out of service on those routes where the wave height recorded exceeds the limit.

From a study carried out by Austal Ships, on board the high speed vessel Stena HSS en route in the Irish Sea, a cancellation rate of only $0.3 \%$ on the basis of 5000 sailings was obtained, a good result if we consider that 
a1\% rate would be acceptable for those ships. We should keep in mind that the Saint George's and North Channels are sheltered from west gales, but are subject to erratic waves caused by gusting winds. This is the case of south winds having an effect of funnelling, developing heavy seas in winds from that quarter in the southern part and heavy seas also in west and northwest gales of force 9 in the northern part. ${ }^{4}$

In our study we have considered the following conditions:

- $\quad$ Conventional ships, those developing up to 23 knots.

- $\quad$ Fast ships (23 to 30 knots) that can operate without speed or course restrictions with wave heights up to 3 metres (Beaufort 6).

- $\quad$ High Speed Vessels that should follow the operational manual, where the operational limitations are scheduled even in the worst possible conditions, establishing the speed reductions:

- Half a knot per each half metre of wave up to 2 metres.

- One knot per each half metre of wave between 2 and 3 metres.

- Two knots per each half metre of wave from this point.

In brief, the next scenarios were analysed:

- $\quad$ For conventional ships (speed less tahn 23 knots), days when the significant wave height would be higher than 4 metres.

- $\quad$ For fast ships: days when the significant wave height would be higher than 3 metres.

- $\quad$ For high speed vessels:

○ Seasickness: days when the significant wave height would be higher than 1.5 metres and would affect a sailing period superior to 2 hours. The trip would be done but $90 \%$ of the passengers would get seasick.

○ Cancellation: days when the significant wave height would be superior to 2.5 metres and would affect a sailing period superior to 2 hours.

5. RESULTS FROM THE ANALYSIS. The weather component was obtained from the comparison of the ship particulars as before stated and the wave height data provided by different oceanographic buoys placed along the selected routes. The wave data has been considered the reference data because spite other meteorological variables as wind speed and direction or fog, the sea state is for safety reasons the parameter used by IMO $^{5}$ and classification societies to establish operational limits for high speed vessels due to their building particularities as less structural resistance and massive use of light materials. Due to these mentioned reasons more sensitive to sea as a conventional steel mono-hull ship.

\footnotetext{
${ }^{4}$ Irish Sea Pilot book. Sea and swell part 1.144 page 25. British Admiralty.

${ }^{5}$ International Maritime Organisation, placed in London.
} 
We have used local boys placed close to the usual ship's tracks because even existing prediction models, for high speed crafts the real data is mostly used as their trips are short and predictions exceeds in general the transit time. Some European projects have dealt on that question as Wings for ships or SPIN-HSV, ${ }^{6}$ being coincident on the fact that the prediction should be corrected with on board observations and giving very short term outputs. However we want to note the on demand and specific services as Meteoconsult or Nowcasting Ltd. among others or the availability of pay free information from prediction models as Meteosim or WAAM, inter alia.

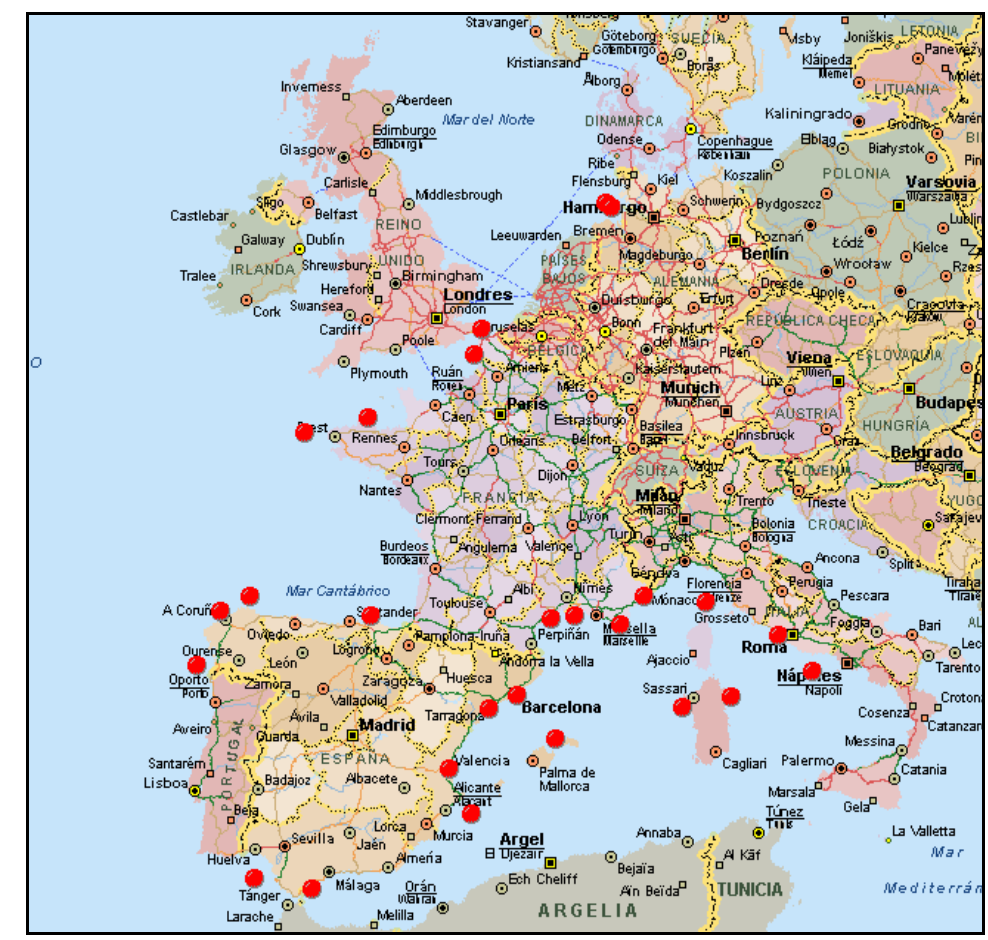

Figure 1: Situation of meteorological buoys close to the selected routes. Source Eurometeo.

Data were obtained mainly from the different addresses below:

- In Spain data is available in the weather and oceanographic information folder on "Puertos del estado" website. There is a link to the physical wave parameter measurement network such as wind, currents, temperatures inter alia, etc. distributed in six different nets depending on the data measured.

- Weather conditions on the German coasts are displayed in the "Bundesamft fur Seeschiffahrt und Hydrographie, BSH" carrying out wave measures in their responsibility area.

- $\quad$ On the French coasts, wave measurements are carried out by the "Centre d'etudes techniques maritimes et fluviales" and the "Centre d'Archivage Nacional de Donnés de Houles In Situ", CANDHIS, and also from www.meteofrance.com.

\footnotetext{
${ }^{6} 5^{\text {th }}$ Framework programme European projects, leaded by METTLE company, focused on high speed crafts performances.
} 
- The Italian coasts are surveyed by the institution "Idromare", providing information on wave heights and wind.

- Information on the waves in the Western Mediterranean is available at http://www.eurometeo.com, (data obtained the 08/02/2006).

The data used has been mainly the significant wave height (Hs), from the information of the selected meteorological buoys shown on the before mentioned websites. The significant wave height $\mathrm{H}_{1 / 3}$ or $\mathrm{H}_{\mathrm{s}}$, is the mean height of the upper observed third.

\begin{tabular}{|lc|}
\hline \multicolumn{1}{|c|}{ Scenarios } & Hs (m) \\
\hline High Speed Craft (HSC) seasickness & $>1,5$ \\
\hline High Speed Craft (HSC) cancellation & $>2,5$ \\
\hline Fast Ro/Pax & $>3$ \\
\hline Conventional & $>4$ \\
\hline
\end{tabular}

Table 3: Selected ships different wave height limits.

We have registered the different wave height ratios in each of the selected routes, keeping in mind the possible route the ship would follow.

- The first route from Valencia to Naples is 710 nautical miles long and passes by Balearic, Sardinia, Cape Comino and Ponza buoys.

- $\quad$ The second route from Barcelona to Civitavecchia, 439 nautical miles long passes close to Sardinia, Cape Comino and Cape Linaro buoys.

- The third route from Alicante to Genoa is 560 nautical miles long and passes close to Alicante, Barcelona, Porquerolles and Nice buoys.

- The fourth route from Tarragona to Genoa is 399 nautical miles long and passes close to Tarragona, Barcelona, Porquerolles and Nice buoys.

- The fifth route from Gijón to Hamburg is 987 nautical miles long and passes close to Gijón, Ouessant, Cherbourg, Dunkirk, Elbe and Helgoland buoys.

\begin{tabular}{|c|c|c|c|c|}
\hline Hs (m) & $\mathbf{> 1 , 5 m}$ & $\mathbf{> 2 , 5 m}$ & $\mathbf{> 3} \mathbf{m}$ & $\mathbf{7 m}$ \\
\hline Alicante & $4,42 \%$ & $0,66 \%$ & $0,24 \%$ & $0,03 \%$ \\
\hline Barcelona & $2,44 \%$ & $0,33 \%$ & $0,04 \%$ & $0,00 \%$ \\
\hline Por querolles & $37,72 \%$ & $12,68 \%$ & $4,14 \%$ & $0,07 \%$ \\
\hline Nice & $1,94 \%$ & $0,11 \%$ & $0,03 \%$ & $0,00 \%$ \\
\hline Tarragona & $2,01 \%$ & $0,11 \%$ & $0,02 \%$ & $0,00 \%$ \\
\hline Gijón & $49,39 \%$ & $17,21 \%$ & $8,39 \%$ & $2,40 \%$ \\
\hline Ouessant & $64,93 \%$ & $39,62 \%$ & $24,33 \%$ & $5,80 \%$ \\
\hline Cherbourg & $1,30 \%$ & $0,00 \%$ & $0,00 \%$ & $0,00 \%$ \\
\hline Dunkirk & $17,80 \%$ & $4,82 \%$ & $2,24 \%$ & $0,00 \%$ \\
\hline Elbe & $23,00 \%$ & $5,30 \%$ & $2,40 \%$ & $0,25 \%$ \\
\hline Helgoland & $23,70 \%$ & $5,50 \%$ & $2,20 \%$ & $0,10 \%$ \\
\hline
\end{tabular}

Table 4: Buoys maximum rate of wave height limits. 
From the analysis of the previous data, we obtained the results displayed in the next table. These results show the maximum percentage of probabilities that each type of ship would have to find the selected wave height level in each route. The table would provide some conclusions, linking the type of ship and its possibility of encountering adverse weather conditions that would disturb the proper sailing of ships, forcing them to reduce speed or even to cancel the trip.

\begin{tabular}{|c|c|c|}
\hline & Type of ship (Scenario) & Maximum ratio of wave height \\
\hline \multirow{4}{*}{ Route 1} & Conventional & $1,96 \%$ \\
\hline & Fast Ro/Pax & $4,94 \%$ \\
\hline & HSC cancellation & $7,69 \%$ \\
\hline & HSC Seasickness & $45,43 \%$ \\
\hline \multirow{4}{*}{ Route 2} & Conventional & $1,04 \%$ \\
\hline & Fast Ro/Pax & $3,88 \%$ \\
\hline & HSC cancellation & $7,33 \%$ \\
\hline & HSC Seasickness & $45,43 \%$ \\
\hline \multirow{4}{*}{ Route 3} & Conventional & $0,07 \%$ \\
\hline & Fast Ro/Pax & 4,14 \\
\hline & HSC cancellation & $12,68 \%$ \\
\hline & HSC Seasickness & $37,72 \%$ \\
\hline \multirow{4}{*}{ Route 4} & Conventional & $0,07 \%$ \\
\hline & Fast Ro/Pax & $4,14 \%$ \\
\hline & HSC cancellation & $12,68 \%$ \\
\hline & HSC Seasickness & $37,72 \%$ \\
\hline \multirow{4}{*}{ Route 5} & Conventional & $5,80 \%$ \\
\hline & Fast Ro/Pax & $24,33 \%$ \\
\hline & HSC cancellation & $39,62 \%$ \\
\hline & HSC Seasickness & $64,93 \%$ \\
\hline
\end{tabular}

Table 5: Maximum probability of the proposed wave heights encounter for each type of ship.

At a first glance it can be said that:

- $\quad$ Route 2 between Barcelona and Civitavecchia offers the best scenario for fast Ro/Pax and even for high speed vessels, with an annual ratio of waves higher than 3 metres of $3.88 \%$ and a cancellation level of about $7 \%$ but with a seasickness ratio of $45 \%$. Obviously, in this analysis we have not 
considered a possible diversion route for avoiding the worst weather, which would reduce those percentages.

- $\quad$ Routes 3 and 4, show the best conditions for conventional ships with only the $0.07 \%$ of cases of wave heights bigger than 4 metres. The seasickness value for high speed vessels is the lowest of the five routes.

- As it was expected, the Atlantic route shows the worst weather conditions on average. The cancellation ratio grows up to $39.62 \%$ and the seasickness ratio up to $65 \%$.

The analysis cannot stop at this point, as the figures should be translated into more useful ones. Considering the frequency or number of trips per year, the distances between ports and the different ship speeds (18 knots for conventional ones, 27 knots for fast Ro/Pax and 40 knots for HSC) we will be able to establish the number of trips per year and the time allowance needed to recover from weather delays.

The conclusions obtained after establishing a determined number of trips per year depending on the distance between ports and the speed developed, are based on the selected buoys statistical information. Regarding the reliability degree of that information it depends on each country system. In Spain for example, buoys reliability is very high and related to data this depends on the period of analysis, as one year can be different to the other one, longer period will be better and we have considered data obtained from website of each country. Also as it was stated, the rate of cancellation is related to a time equal or superior than 2 hours, in which the wave limit exceeds the maximum affordable. The question is that the buoys cover a sea extension to be sailed during more than such period of time, because even in the case of a high speed craft, this should reduce the speed when sea state deteriorates. Id est, for the Barcelona to Civitavecchia line, there are 439 miles to be covered and 4 buoys used to get the information on sea state.

However all the routes lasts for more than two hours. It is compulsory for ships, to have an alternative track to be followed in case of bad weather as for example the case of Tarragona to Genoa trip, where the ship would sail close to the French coast. However these scenarios would need a more in deep study as the distance and developed speeds are different and we could give no feasible conclusion, based on supposed routes.

The used criteria for determine the mentioned cancellation rates on high speed crafts are based on the information given to the master on the sea state is (or expected to be) worse than the ship's safe operational limit. Then he must decide to cancel the trip. The discussion point is that where is the worst sea state registered?. The last decision is on the master's hand and he can decide to sail provided that the bad weather is only in the last part of the trip. The prediction models are useful to provide ahead information on the weather to be found but it is needed with anticipation enough provided the ship's speed. The conclusion gives the maximum number of cancellations considering the maximum rate of highest wave height higher than the operational limits. ${ }^{7}$

\footnotetext{
${ }^{7}$ Informe ICARO: Seguridad e información meteorológica. ICARO project, Barcelona 2006.
} 
6. CONCLUSIONS. The first route can be served by two conventional ships that would sail three times per week from each port and stop on Sunday, with a ratio of $2 \%$ of wave height higher than 4 metres. The fast ship developing 27 knots offers more cargo capacity after one year because she can do more trips per week. In this case we have reduced the ship's speed from 27 to 25 knots in order to delay the port arrival up to a daylight time. This ship has a ratio of wave height higher than 4 metres of only 5\%. For the high speed vessels they must assume a yearly cancellation ratio of $8 \%$ together with a high percentage of seasickness. On the other hand the ship stays 3 hours more than the time required for cargo operations, which can be used as time to recover from delays.

Among the three possible types of ships in the second route we can say that the conventional and HSC ships have less capacity on a weekly basis. The weather affects less the fast Ro/Pax as these ships can do more trips per week.

Route number 2 between Barcelona and Civitavecchia, should be served by fast Ro/Pax because the ship stays at port for 7 hours each day, so that there is a time allowance in front of possible weather delays. In this case there is a $4 \%$ of time affected by significant wave height higher than 3 metres.

Route number 3 between Alicante and Genoa provides a good scenario for the conventional ship as she only faces a $0.07 \%$ of time with some trouble due to weather. Fast ships have a tight schedule for completing six trips per week, so it would be better to reduce them to5 in order to have room to assume the $4 \%$ of time sailing at a reduced speed. High speed ships are 7 hours at port even sailing at less than 40 knots, so a reduced schedule could be studied.

Route number 4 between Tarragona and Genoa has a very slight weather influence, so that the ship selection could be based on the market needs. The fast Ro/Pax suffers a $4 \%$ of speed reduction because of weather, being 5 hours at each port and having a time margin to recover it. The high speed ship can offer up to 9 trips per week and a good yearly loading ratio; however, her time schedule is very tight.

Finally route number 5 between Gijón and Hamburg, logically suffers the worst weather conditions as a conventional ship faces up to a $6 \%$ of time wave heights higher than 4 metres with one day possibility to recover the line. The fast ship faces up to a $24 \%$ of time significant waves higher than 3 metres, but she is at port for 7 hours each trip. The high speed ship stops for 14 hours one time per week, but the cancellation ratio reaches the $39 \%$ per year.

Generally the fast Ro/Pax seems to be the best option. In spite of having a superior transit time she has the best reliability level, compared to a high speed ship. The yearly cancellation ratio is shown in the table below, being bigger as the ship speed increases. There is left a more in deep analysis where the cancellation rate could be related to the exact time and place of occurrence, considering the actual ship's position. We think that the rate could be reduced thanks to a more precise information. 


\begin{tabular}{|l|l|c|c|}
\hline \multicolumn{1}{|c|}{ Route } & \multicolumn{1}{|c|}{ Ship's type } & \% yearly cancellation & Cancelled trips per year \\
\hline \multirow{2}{*}{ Route 1 } & Fast Ro/Pax & $3 \%$ & 6 \\
\cline { 2 - 4 } & High Speed Ship & $7 \%$ & 22 \\
\hline Route 2 & Fast Ro/Pax & $1 \%$ & 4 \\
\cline { 2 - 4 } & High Speed Ship & $6 \%$ & 28 \\
\hline Route 3 & Fast Ro/Pax & $4 \%$ & 13 \\
\cline { 2 - 4 } & High Speed Ship & $9 \%$ & 28 \\
\hline Route 4 & Fast Ro/Pax & $1 \%$ & 3 \\
\cline { 2 - 4 } & High Speed Ship & $11 \%$ & 51 \\
\hline Route 5 & Fast Ro/Pax & $12 \%$ & 63 \\
\cline { 2 - 4 } & High Speed Ship & $30 \%$ & 19 \\
\hline
\end{tabular}

Table 6: Maximum yearly cancellation ratio and total number of cancelled trips, for the fast and high speed ships.

\section{REFERENCES}

Blonk. W. (2003). Prospects and challenges of Short-sea Shipping. Proceedings from the second European research roundtable conference on short-sea shipping.

European Commission. (2001). European Transport Policy for 2010: Time to decide. Brussels.

European Commission. (2005). High Level Group of the European Commission. Extension of the Major TransEuropean Transport Axes to the Neighbouring Countries and Regions. Brussels.

European Commission. (2006). Mid-term review of the European Commission's 2001 White paper on transport. Brussels.

Hydro graphic department. Minstry of defence. Irish Sea Pilot book. Taunton, Somerset. England.

International Maritime Organisation. (2001). International Code for High Speed Crafts. London.

Martínez de Osés, F.X. (2006). Informe ÍCARO: Seguridad e información meteorológica, https://eprints.upc.edu/handle/2117/532, Barcelona.

Martínez de Osés, F.X., Castells, M. (2006). Análisis de los buques en el Short Sea Shipping Español, http://hdl.handle.net/2117/554

Martínez de Osés, F.X. (2006). El navegante y las olas. Boletín de la Asociación Meteorológica Española, Volume 11, pg. 24 a 28. Barcelona.

NEA Institute. (2006). Short sea Shipping study. Netherlands .

Olivella J., Martínez de Osés, F.X., Castells, M. (2006). Las autopistas del mar como alternativa al tráfico de los Pirineos. Barcelona digital, SL. Barcelona.

Olivella J., Martínez de Osés, F.X., Castells, M. (2005). Intermodalidad entre España y Europa. El proyecto

INECEU. Barcelona digital, SL. Barcelona.

http://www.bsh.de, consulted the 12/02/2006.

http://www.cetmef.equipement.gouv.fr/, consulted the 10/02/2006.

http://www.idromare.com, consulted the 16/02/2006.

http://www.puertos.es, consulted on 12/02/2006. 